\title{
Oscillating rotary electrical machine for Stirling cycle heat pump and other devices of renewable energy
}

\author{
S. Kudarauskas ${ }^{1}$, J. Ulbikas ${ }^{2}$ and T. Razvanovičius ${ }^{1}$ \\ ${ }^{1}$ Applied Research Institute for Prospective Technologies "ProTech" \\ Sauletekio al. 15, LT-10224 Vilnius (Lithuania) \\ Phone number: +370 627 09945, e-mail: kudarauskas@klaipeda.omnitel.net, tomas@met.lt \\ 2 JSC "EuroParama" \\ Sauletekio av. 15, LT-10224 Vilnius (Lithuania) \\ Phone/Fax number: +370 5 2500616, e-mail: juras.ulbikas@europarama.It
}

\begin{abstract}
The paper deals with oscillating rotary electrical machines, that is with periodical angular movement of their movable part. Expedient application of all oscillating electrical machines consists in possible avoidance of mechanical transformer in the drive, according to the direct drive principle. That is why oscillating electrical machines are suitable to use with positive displacement thermal machines.

In the paper, principles of development of the Stirling cycle heat pump with oscillating rotary electrical motors according to the project EFFiHEAT are presented. Partners from Spain, Bulgaria and Lithuania are implementing the project.
\end{abstract}

Tentative test of the oscillating rotary motor prototype confirms its working capacity and advantages.

Principles of presented structure can be used in various other devices of renewable energy (e. g. solar power stations, geothermal power plants, heat and power cogenerators, generators with multi-fuel Stirling engine etc.).

\section{Key words}

Oscillating rotary electrical machines, oscillating linear electrical machines, free-piston thermal machines, Stirling cycle devices.

\section{Introduction}

Devices of electromechanical energy conversion (that is, electrical machines) are an integral part of majority renewable energy systems. Not always conventional electrical machines with continuous rotation of their movable part (the conventionality from a viewpoint of used mechanical movement) are the best for such devices. Therefore in some cases electrical machines with special properties of the movement are proposed. For example, so-called linear electrical machines are known. Unfortunately, the term linear is not exhaustive for such special electrical machines, because it reflects only spatial property of mechanical movement, whereas a temporal property of the movement is also very significant.

Thus, it is necessary to distinguish mutually independent temporal and spatial properties of movement in electrical machines. According to temporal properties, machines of continuous, periodical (oscillating), impulse movement can be marked, and according to spatial properties rotary, linear machines, and ones with complex trajectory of movement [1]. Consequently, this paper deals with oscillating rotary electrical machines (when periodically varying position of the movable part is defined by its angular coordinate).

It is expedient to use oscillating electrical machines according to the direct drive principle, i.e. with mechanisms using the corresponding oscillation of their movable parts. In that case, the mechanical motion transformer can be avoided. Consequently, one of the expedient usages of oscillating electrical machines is their operation with positive displacement thermal machines (i.e. with piston devices), including Stirling cycle devices.

It is noticed that the unit of oscillating machine and piston thermal machine enables to reach the free-piston effect, i.e. the variable and controllable by means of electronics piston stroke.

Heat pumps are one of prospective renewable energy devices. In the paper, some results of development of the oscillating rotary electrical motor for high efficiency Stirling cycle heat pump according to project EFFiHEAT [2] are presented. This project is pursued by partners from Spain (Mondragon Components, and CS Centro Stirling S. Coop), Bulgaria (Sofia University), and Lithuania (Applied Research Institute for Prospective Technologies ProTech, and JSC "Modern E-Technologies" MET). 


\section{Oscillating electrical machines with piston devices}

\section{A. Samples of the devices}

There are known many various piston devices operating with oscillating electrical machines. It is to note that such first device (the air compressor) was tested more than hundred years ago by Paul Boucherot [3].

Nowadays the corresponding Stirling cycle devices are produced by Sunpower Inc. for many years [4]. An example of such cryocooler is shown in Fig. 1.

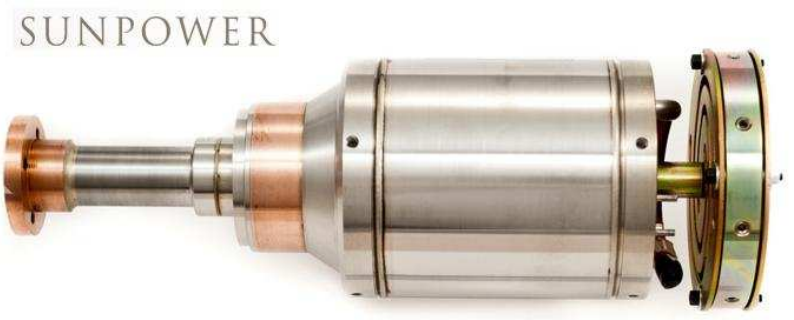

Fig. 1. Cryocooler of Sunpower Inc. [4].

It is to note that Sunpower Inc. (that declares is being "The world leader in free-piston Stirling engines and cryocoolers") and many other producers of analogous devices are proposing only linear variants of the freepiston thermal machines and oscillating electrical machines. Though these devices are characterised by advantages of the direct drive principle (avoidance of movement transformer, minimised number of frictional pairs etc.), unfortunately, some shortcomings also are specific to the linear devices: non-optimal magnetic circuit of oscillating linear machines, non-balanced mechanical part of the device etc.

Mentioned above shortcomings of linear devices can be observed in many other proposed structures. For example, non-used parts of the linear alternator driving by freepiston internal combustion engine are apparent in socalled Free Piston Energy Converter shown in Fig. 2 [5].

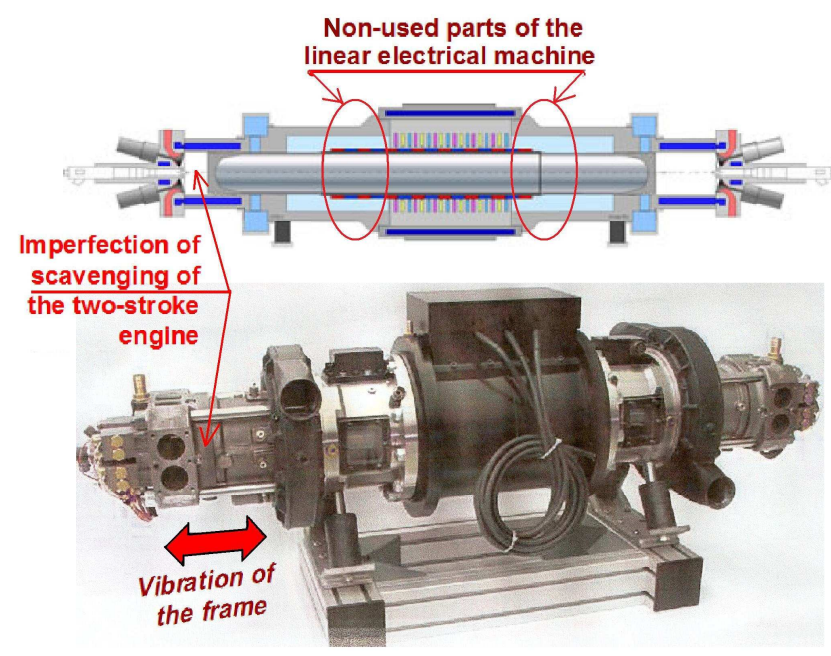

Fig. 2. Principal layout and photograph of the prototype of socalled Free Piston Energy Converter [5].
Taking into account the mentioned above disadvantages of the considered linear devices, it is expedient to look for structures of the unit with rotary oscillation of the movable parts.

\section{B. Character of variation of the permeances}

Operation of all electrical machines with storage energy in the magnetic field is grounded by dependence of permeances on the position of movable part [1]. In majority of oscillating electrical machines, variable permeances are monotonous functions of the movable part coordinate. As a rule in this case, induced in the machine windings electromotive forces alternate with the same frequency as oscillation of the movable part. This situation can limit specific power of the oscillating machine, if the mechanical oscillation frequency is low.

Known oscillating electrical machines of Sunpower Inc. use monotonous variation of permeances, and creators of these machines have stated mentioned above limitation of the specific power: "A $25 \mathrm{kWe} F P S E$ / generator of this configuration was designed in the early 1990' $s$ but not built. Larger sizes as single units are feasible but unlikely to be commercially viable, as alternator volumes become excessive" [6] (here FPSE - free piston Stirling engine).

There are known oscillating electrical machines with multiextremal variation of permeances [1]. Sample of such oscillating linear machine is shown in Fig. 2. In this case, the frequency of induced electromotive force is higher than frequency of oscillation, and specific power is higher too. Therefore it is expedient to choose the corresponding structure of oscillating rotary motor for Stirling cycle heat pump.

\section{Structure of the Stirling cycle heat pump}

\section{A. Principle of structure}

Structure of oscillating rotary electrical machine and Stirling cycle heat pump is grounded by authorial patent [7]. So, a volumetric thermal machine can be created using angular (rotary) oscillations of vane-shaped pistons in the cylindrical cavity, and this thermal machine can operate with the corresponding oscillating electrical machine. Principle of structure of the proposed freeswinging piston thermal machine with the oscillating rotary electrical machine is shown in Fig. 3.

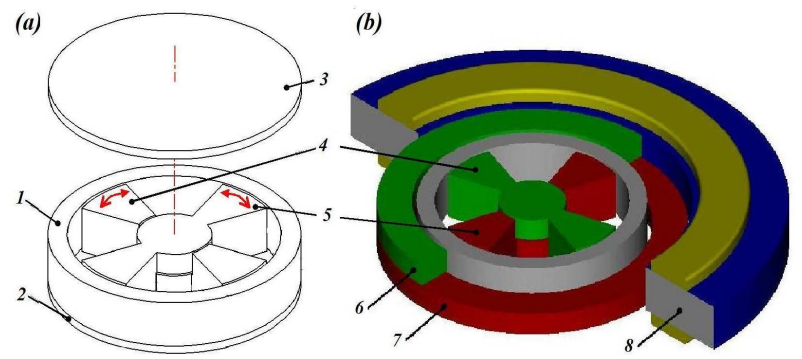


Fig. 3. Principle of structure of the free-swinging piston thermal machine $(a)$, and structure of a unit with the oscillating rotary electrical machine $(b)$.

The free-swinging piston thermal machine consists of a housing with a cylindrical cavity (e.g., formed by cylindrical ring 1 and covers 2, 3, Fig.3,a) in which two analogous assemblies of vane-shaped pistons 4, 5 are arranged. The piston assemblies are directly connected with rotors 6,7 of the oscillating electrical machine (hawing stator 8), and these components oscillate in opposite directions, forming four (as minimum) working chambers of the thermal machine.

The main advantages of such device are as follows:

- compactness (decreased up to $50 \%$ the weight and volume),

- minimum frictional losses in the rotary guide,

- reduced (or absent) wear of the pistons and cylinder (housing) surfaces,

- possibilities to simplify sealing and lubrication,

- full-balanced mechanical system without vibration of the frame,

- optimal magnetic circuit of the oscillating rotary electrical machine,

- possibility to control the free-swinging piston thermal machine via the oscillating electrical machine by means of electronics.

\section{B. Principle of Stirling cycle heat pump}

On a base of the structure shown in Fig. 3,b, the Stirling cycle device may be created too. The most advantaged Stirling cycle device with linear pistons is the multicylinder one shown in Fig.4.

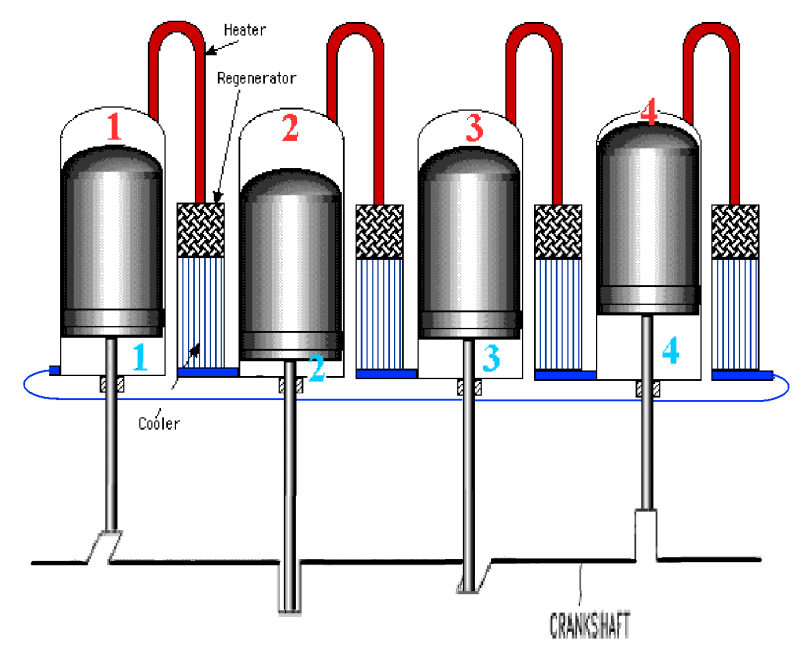

Fig. 4. Conventional multi-cylinder Stirling device.

As we can see, the conventional multi-cylinder Stirling cycle device has eight working chambers. Therefore the analogous device with oscillating rotary electrical machines and vane-shaped pistons must be composed of two corresponding units. Principal layout of possible Stirling device is shown in Fig. 5. The device consists of the doubled free-swinging piston heat machines 1' and 1", and two oscillating rotary electrical machines 2 ' and 2", each hawing two rotors. The device includes heater 3, regenerators 4 , and cooler 5. According to this structure, various Stirling cycle devices can be created (engines, refrigerators, coolers, heat pumps).

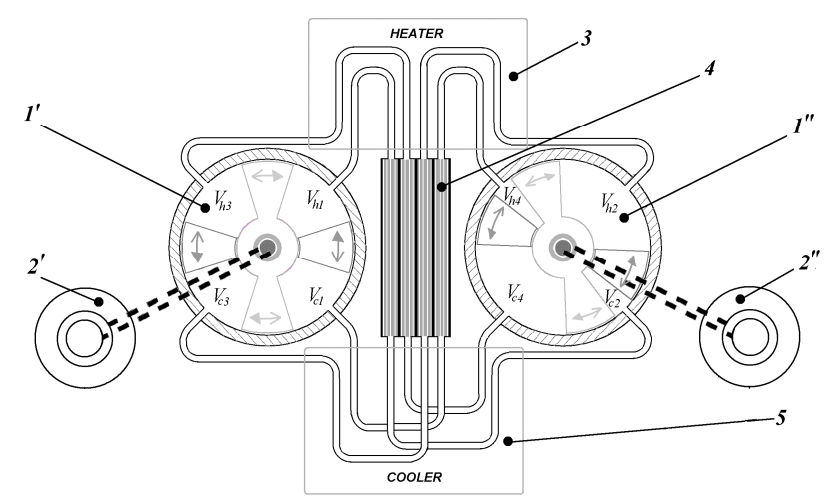

Fig. 5. Principal layout of possible free-swinging piston Stirling machine and oscillating rotary electrical machine.

\section{Technological objectives of EFFiHEAT project}

The technological objectives of the developed Stirling cycle heat pump are presented in table I [2].

Table I

\begin{tabular}{|l|c|}
\hline \multicolumn{1}{|c|}{ Technology performance attribute } & Value \\
\hline $\begin{array}{l}\text { Coefficient of performance at } 0 / 35^{\circ} \mathrm{C} \\
\text { temperature difference (DIN EN 255) }\end{array}$ & 5.3 \\
\hline $\begin{array}{l}\text { Coefficient of performance at 0/50 }{ }^{\circ} \mathrm{C} \\
\text { temperature difference (DIN EN 255) }\end{array}$ & 4.2 \\
\hline Woking gas & $\begin{array}{c}\text { Air or } \\
\text { helium }\end{array}$ \\
\hline Operating range & $5 / 55^{\circ} \mathrm{C}$ \\
\hline Power input (min. - rated - max) & $1-2-3 \mathrm{~kW}$ \\
\hline Heating capacity & $5-15 \mathrm{~kW}$ \\
\hline Sound pressure level & $<40 \mathrm{~dB}(\mathrm{~A})$ \\
\hline $\begin{array}{l}\text { Initial cost savings (in comparison with } \\
\text { technologies in operation) }\end{array}$ & $30 \%$ \\
\hline
\end{tabular}

According to these technological objectives, the design of the oscillating motor and heat pump was performed. Estimated power flows are shown in Fig. 6

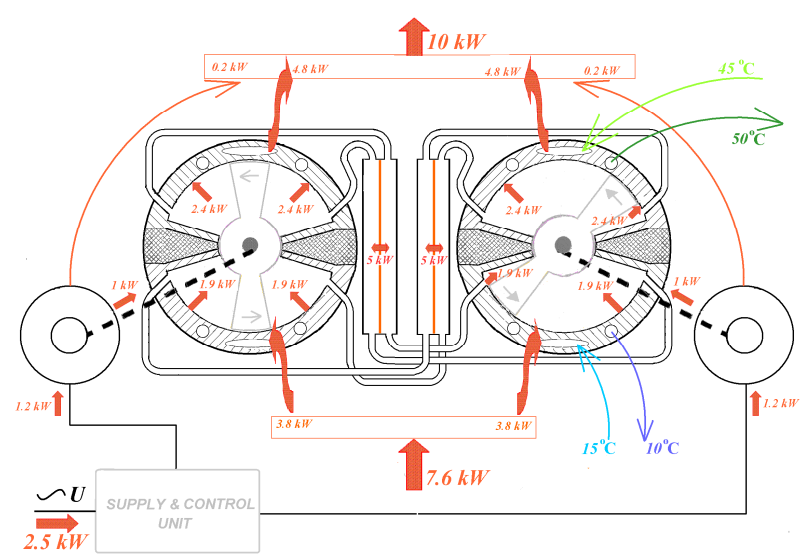

Fig. 6. Estimated power flows of the heat pump. 
In Fig. 6, a simplified structure of the vane-shaped positive displacement thermal machines of the Stirling cycle heat pump is shown: here one vane-shaped swinging piston and fixed dividing walls are used in each thermal machine instead of twin vane-shaped pistons. In this case, the oscillating rotary motors have only one rotor. This simplified structure is not well-balanced, but it is chosen for the first device prototype.

\section{Oscillating rotary motor prototype}

Pursuing EFFiHEAT project, a prototype of the heat pump was designed and put out. The main parts of oscillating rotary motors were designed by Lithuanian partners of the project.

Principle of chosen structure of the oscillating rotary motor is shown in Fig. 7. The motor has inner and outer stators. The hollow rotor with permanent magnets is placed between the stators. The two-phase winding is arranged on the outer stator. In principle, the outer stator with multi-phase winding does not differ from the stator of conventional rotary AC electrical machines. Thus, the motor magnetic circuit is closed and optimal.

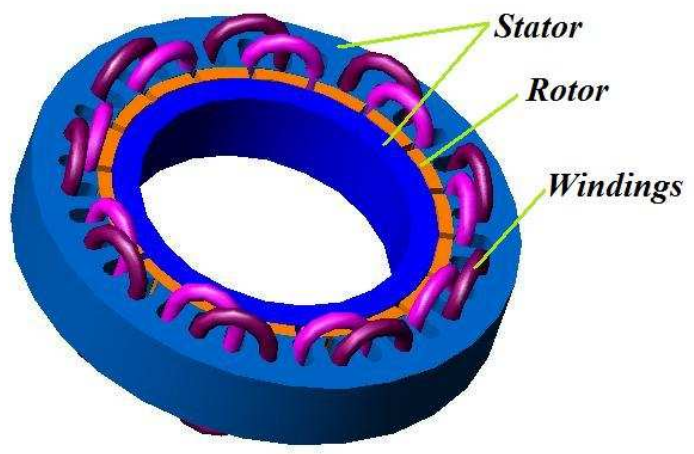

Fig. 7. Principle of oscillating rotary motor structure.

The motor parameters were defined as rezult of analysis of the magnetic field by FEMM software (Fig. 8).

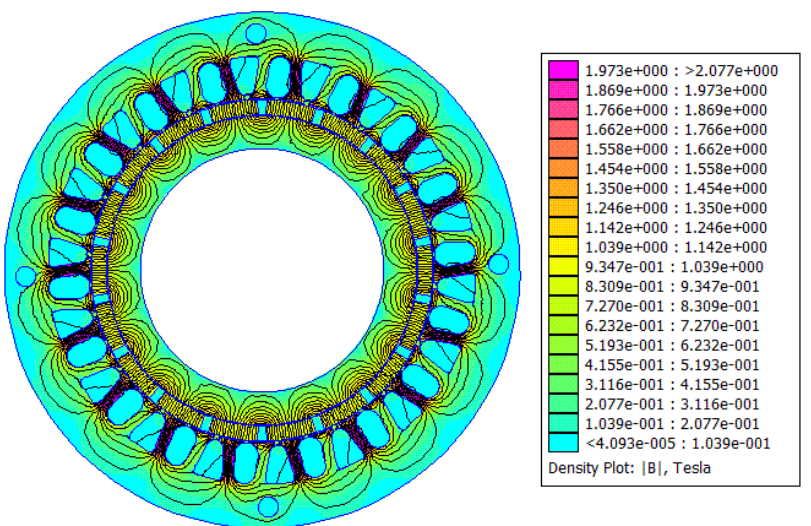

Fig. 8. Answer of magnetic field calculation.

Analysis of the magnetic field enabled receive the main characteristics of oscillating motor as torque $T$ and flux linkage $\Psi$ functions of rotor coordinate $\alpha$ and current $I$ :

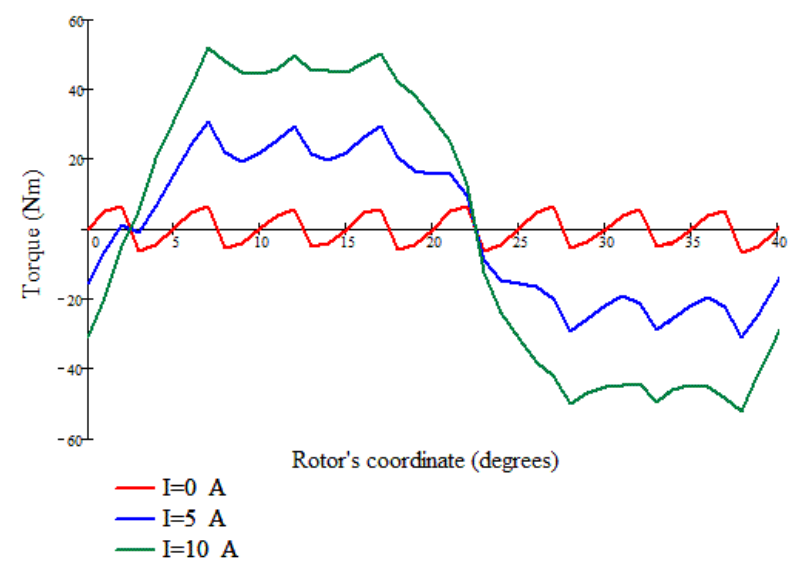

Fig. 9. Torque as function of rotor's coordinate and current.

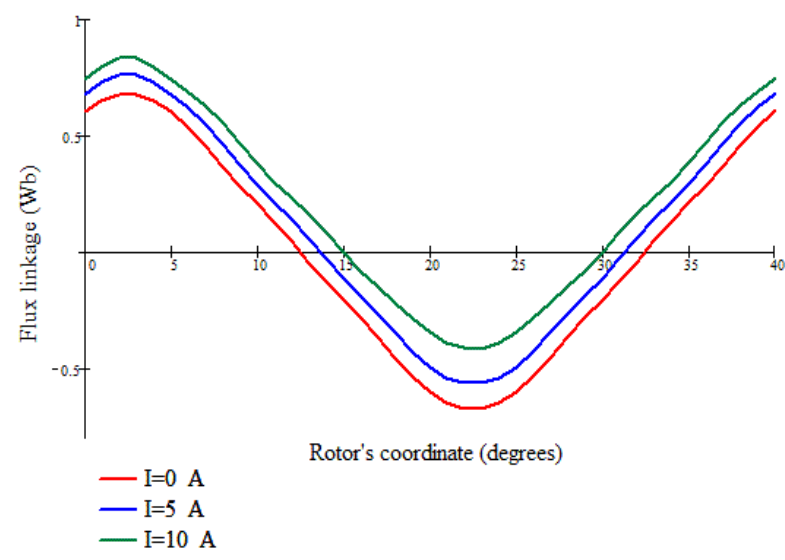

$T(\alpha, i), \quad \Psi(\alpha, i)$.

Graphics of these functions are presented in Fig. 9 and 10 (for one pole pitch).

Fig. 10. Flux linkage as function of rotor's coordinate and current.

Operation of the two-phase oscillating rotary motor \& Stirling cycle heat pump is described by following differential equations:

$$
\begin{aligned}
u_{A}(t) & =r \cdot i_{A}-\frac{d \Psi\left(\alpha, i_{A}\right)}{d t}, \\
u_{B}(t) & =r \cdot i_{B}-\frac{d \Psi\left(\alpha, i_{B}\right)}{d t}, \\
T_{A}\left(\alpha, i_{A}\right)+T_{B}\left(\alpha, i_{B}\right) & =J \frac{d \Omega}{d t}+R \cdot \Omega+c \cdot \alpha+T_{S} ;
\end{aligned}
$$

here $u_{A}(t), u_{B}(t)$ are supply voltages of phases $A$ and $B$ (as time functions), $r$ is the resistance of windings, $J$ is the moment of inertia, $\Omega$ is the angular speed, $R$ is the 
mechanical resistance of losses, $\mathrm{c}$ is the possible spring constant, $T_{S}$ is the loading torque of Stirling device. Solution of the differential equations enables to form performance characteristics of the device.

An amplitude of rotor oscillation may be controlled, and it can cover several pole pitches. In this case, variation of the mutual permeance between magnetomotive forces of stator and rotor is multiextremal. This situation enables to reach high performances in terms of the specific power, but this structure slightly complicates the motor control system (in compare to the control system of the oscillating motor with monotonous variation of permeances).

Tentative test of the oscillating rotary motor prototype shows satisfactory coincidence of calculated and measured parameters of the motor, and its working capacity.

\section{Conclusion}

The proposed oscillating rotary electrical machine and their application with swinging pistons Stirling cycle heat pump is advantaged to compare with known analogous linear devices.

It should be noted that the presented principle of structure of the oscillating rotary electrical machine $\&$ vane-shaped swinging piston heat machine can be used in various other devices of renewable energy (e. g. solar power stations, geothermal power plants, heat and power cogenerators, generators with multi-fuel Stirling engine etc.).

\section{References}

[1] S. Kudarauskas, Introduction to Oscillating Electrical Machines, Klaipeda University, Klaipeda (2004).

[2] http://www.effiheat.eu

[3] P. Boucherot, "Appareils et machines à courant et mouvement alternatifs", in Bulletin de la Société internationale des Electriciens, Paris, 1908, pp. 731-755.

[4] http://www.sunpower.com

[5] E. Max, "FPEC, Free Piston Energy Converter", in Proc. of EVS 21, Monaco, 2005, pap. 159.

[6] J.G. Wood, N.W. Lane, W.T. Beale, "Preliminary Design of a $7 \mathrm{kWe}$ Free-Piston Stirling Engine with Rotary Generator Output", in proc. of 10th Inernational Stirling Engine Conference, 2001.

[7] S. Kudarauskas, "Free-swinging piston heat machine", patent US 7827901, Nov.9, 2010. 